\title{
PENGUKURAN USABILITY WEBSITE E-COMMERCE SAMBAL NYOSS MENGGUNAKAN METODE SKALA LIKERT
}

\author{
Ryan Ari Setyawan ${ }^{1}$, Walter F. Atapukan ${ }^{2}$ \\ Program Studi Teknik Informatika, Fakultas Teknik \\ Universitas Janabadra \\ Jl. Tentara Rakyat Mataram No 55-57 Yogyakarta \\ ryan@janabadra.ac.id ${ }^{1}$
}

\begin{abstract}
The purpose of this study is to measure the usability or usefulness of e-commerce website sambal nyoss by using Likert scale. Likert scale serves to determine the scale category from 1 to 5. The methodology in this research is using the waterfall software design methodology. The results of e-commerce web testing on usability testing using the Likert scale method can be concluded that the average Likert Score of the usability test is 4 . The value of 4 in the likert scale is the category agreed, so the usability level can be accepted by the user. The test results also mean that web ecommerce samboss nyoss has met usability aspect values such as ease of system, easy to remember system, efficiency, no errors or errors and have a level of user satisfaction
\end{abstract}

Keywords: e-commerce, skala likert, usability.

\section{Latar Belakang Masalah}

Perkembangan teknologi informasi saat ini sangatlah pesat, dimana akses internet bukan menjadi sesuatu yang mahal namun sudah menjadi kebutuhan. Para pengguna internet dimudahkan dengan mendapatkan informasi secara praktis kapanpun dan dimanapun. Adanya akses internet mudah tersebut membuat bergesernya model konvesional beralih ke model serba digital dan elekronik. Seperti halnya pada pasar saat ini sudah mulai bergeser dengan munculnya pasar online.

Pasar online tersebut memudahkan pembeli dan penjual untuk melakukan transaksi secara mudah, praktis dan efisien. Hanya melalui aplikasi atau website kemudian tinggal klik para pembeli dan penjual sudah dapat melakukan transaksi sehingga tidak perlu bertemu langsung. Hal tersebut tentunya membuat bergesernya cara konvensional dan beralih ke model online. Tentunya dari hal tersebut pelan-pelan mulai menghilangkan cara konvensional yang ada terutama bagi pelaku ekonomi kreatif yang selama ini menggunakan cara tersebut.

Pelaku ekonomi kreatif tersebut diantaranya adalah UMKM atau usaha mikro kecil menegah. UMKM saat ini tumbuh subur di berbagai daerah. Adanya UMKM tersebut diharapkan masyarakat mampu hidup secara mandiri dan sejahtera, sehingga dapat menekan angka pengangguran menjadi kecil. Namun bila dilihat saat ini, hampir sebagian besar para pelaku UMKM masih menggunakan cara konvesional untuk memasarkan produk dan melakukan transaksi jual beli. Oleh sebab itu untuk memajukan UMKM tersebut sangatlah diperlukan suatu media untuk membantu memudahkan dalam melakukan transaksi jual beli atau memasarkan produk. Salah satunya UMKM Sambal Nyoss, UMKM Sambal Nyoss merupakan UMKM ada di Desa Temon Glagah Kulon Progo Yogyakarta. UMKM tersebut banyak sekali menghasilkan produk abon cabe, sambal nyoss, keripik gethuk dan bubuk cabe. UMUKM tersebut juga sangat membutuhkan media untuk dapat mempromosikan produk-produknya.

Media tersebut contohnya adalah website e-commerce. E-commerce merupakan salah satu teknologi yang berkembang pesat untuk transaksi pembelian dan penjualan barang dan jasa melalui 
jaringan elektronik. E-commerce juga merupakan salah satu website yang saat ini sedang populer, sebab hampir semua perusahaan jual beli online rata-rata menggunakan website tersebut.

Melihat situasi tersebut maka sangatlah perlu pengembangan website $e$-commerce untuk UMKM. Tujuannya agar pelaku UMKM mendapatkan meningkatkan pangsa pasar yang luas dan berkelanjutan. Namun dalam proses pengembangan website e-commerce tersebut sangat dibutuhkan metode untuk mengukur tingkat kepuasan pengguna dalam menggunakan website ecommerce.

\section{Metodologi Penelitian}

Metodologi penelitian yang digunakan dalam penelitian ini yakni dengan menggunakan metode perancangan perangkat lunak waterfall. Namun sebelum menjelaskan mengenai metode tersebut, pada uraian ini akan menjelaskan terlebih dahulu mengenai landasan teori yang mendukung.

\subsection{E-commerce}

E-commerce merupakan salah satu teknologi yang berkembang pesat pada pembelian dan penjualan barang dan jasa melalui jaringan elektronik. E-commerce merupakan suatu himpunan dinamis antara teknologi, aplikasi dan proses bisnins yang menghubungkan perusahaan, konsumen, dan komunitas tertentu melalui transaksi elektronik dan perdagangan barang, pelayanan, dan informasi yang dilakukan secara elektronik [1].

\subsection{Website}

Website adalah salah satu aplikasi yang berisikan dokumen-dokumen multimedia (teks, gambar, suara, animasi, video) yang didalamnya menggunakan protokol HTTP (Hyper Text Transfer Protocol) dan untuk mengaksesnya mengguanakan perangkat lunak yang disebut browser. Beberapa jenis browser yang populer saat ini diantaranya adalah Internet Explorer, Google Chrome, Mozzila Firefox, Opera, dan Safari.

Browser atau perambah adalah aplikasi yang mampu menjalankan dokumen-dokumen web dengan cara diterjemahkan. Prosesnya dilakukan oleh komponen yang terdapat didalam aplikasi browser yang biasa disebut web engine. Semua dokumen web ditampilkan dengan cara diterjemahkan [2].

Website merupakan kumpulan dari halaman-halaman yang berhubungan dengan file-file lain yang saling terkait. Dalam sebuah website terdapat satu halaman yang dikenal dengan sebutan home page. Homepage adalah sebuah halaman yang pertama kali dilihat ketika seseorang mengunjungi sebuah website [3].

\subsection{Data Flow Diagram}

Data Flow Diagram atau DFD adalah suatu model logika data atau proses yang dibuat lebih mendetail dibandingkan diagram konteks yang diperbolehkan, dapat dicapai dengan mengembangkan diagram. Sisa diagram asli dikembangkan ke dalam gambaran yang lebih terperinci yang melibatkan tiga sampai sebilan proses dan menunjukkan penyimpanan data dan aliran data baru pada level yang lebih rendah [4].

\subsection{Usability}

Usability merupakan bagian dari ilmu Human Computer Interaction (HCI), usability yakni berasal dari kata usable artinya adalah dapat digunakan dengan baik sehingga sesuatu dapat dikatan 
dengan baik apabila kegagalan dalam penggunaanya dihilangkan dan diminimalkna serta memberi manfaat dan kepuasan kepada pengguna.

Usability dapat juga dikatakan sebagai sejauh mana suatu produk dapat digunakan oleh pengguna tertentu untuk mencapai target yang ditetapkan dengan efektivitas, efesiensi dan mencapai kepuasan penggunaan dalam konteks tertentu. Konteks penggunaan terdiri dari pengguna, tugas, peralatan (hardware, software dan material). Berdasarkan definisi tersebut usability diukur berdasarkan komponen : [5]

a. Kemudahan (learnability) didefinisikan seberapa cepat pengguna mahir dalam menggunakan sistem serta kemudahan dalam penggunaan menjalankan suatu fungsi serta apa yang pengguna inginkan dapat meraka dapatkan.

b. Efisiensi (efficiency) didefenisikan sebagai sumber daya yang dikeluarkan guna mencapai ketepatan dan kelengkapan tujuan.

c. Mudah diingat (memorability) didefinisikan bagaimana kemapuan pengguna mempertahankan pengetahuannya setelah jangka waktu tertentu, kemampuan mengngat didapatkan dari peletakkan menu yang selalu tetap.

d. Kesalahan dan keamanan (errors) didefinisikan berapa banyak kesalahan-kesalahan apa saja yang dibuat pengguna, kesalahan yang dibuat pengguna mencangkup ketidaksesuaian apa yang pengguna pikirkan dengan apa yang sebenarnya disajikan oleh sistem.

e. Kepuasan (satisfaction) didefinisikan kebebasan dari ketidaknyamanan, dan sikap positif terhadap penggunaan produk atau ukuran subjektif sebagaimana pengguna merasa tentang penggunaan sistem.

\subsection{Metode Skala Likert}

Metode Skala Likert merupakan metode yang digunakan untuk menggukur tingkat kepuasan pengguna menggunakan skala likert. Skala likert adalah skala pengukuran yang dikembangkan oleh Likert pada Tahun 1932. Skala likert memiliki empat atau lebih butir-butir pertanyaan yang dikombinasikan sehingga membentuk sebuah skor atau nilai yang mempersentasikan sifat individu, misalkan pengetahuan, sikap dan perilaku. Skala likert dapat juga dikatan sebagai skala psikometrik yang umum digunakan dalam kuesioner dan merupakan skala yang paling banyak digunakan untuk penelitian. Skala likert dapat diperlihatkan pada Tabel 1.1. [6]

Tabel 1. Skala Likert

\begin{tabular}{|c|c|}
\hline Skala & Kategori \\
\hline 1 & Sangat Setuju \\
\hline 2 & Setuju \\
\hline 3 & Cukup \\
\hline 4 & Kurang Setuju \\
\hline 5 & Tidak Setuju \\
\hline
\end{tabular}

\subsection{Desain Sistem}

Desain sistem menggambarkan bagaimana suatu sistem dibentuk. Desain Sistem Ecommerce Sambal Nyoss ini dibuat menggunakan Context Diagram dan Data Flow Diagram.

\subsubsection{Context Diagram}

Diagram konteks (Context Diagram) merupakan tingkatan tertinggi dalam diagram aliran data dan hanya memuat satu proses dan menunjukkan sistem secara keseluruhan. Diagram konteks (Context Diagram) Sistem E-commerce Sambal Nyoss dapat dilihat pada gambar dibawah ini : 


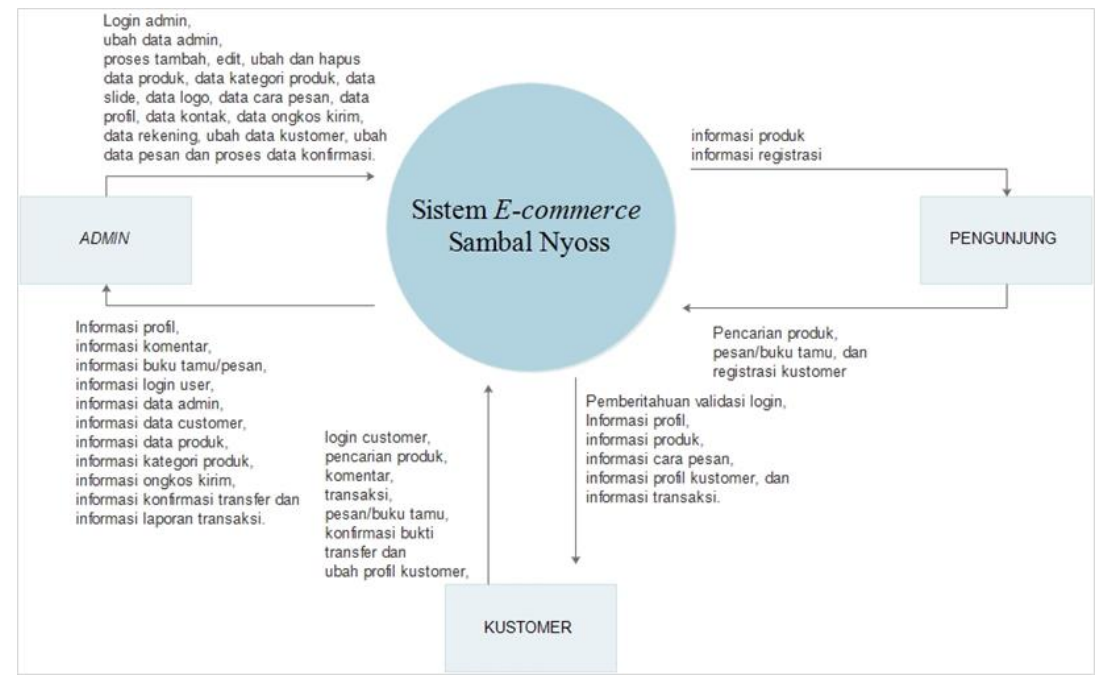

Gambar 1. Context Diagram

\subsubsection{Data Flow Diagram}

Data Flow Diagram merupakan suatu model logika data atau proses yang dibuat untuk mengambarkan asal data dan tujuan data yang keluar dari sistem, tempat penyimpanan data. Interaksi antara data yang tersimpan pada proses yang berhubungan pada data tersebut. Data Flow Diagram (DFD) Sistem E-commerce Sambal Nyoss diperlihatkan pada Gambar 2.

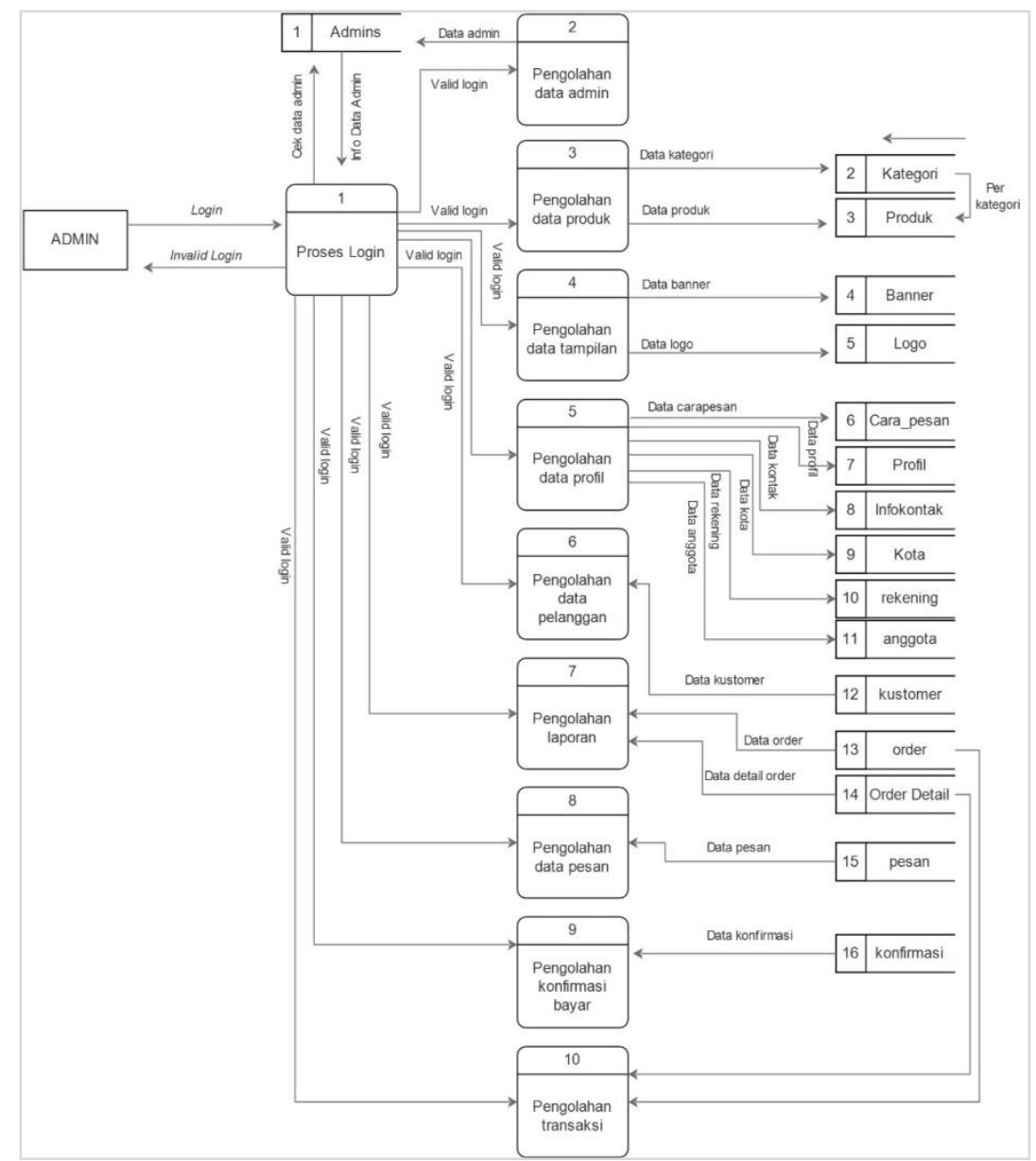

Gambar 2. DFD E-Commerce Sambal Nyoss 


\section{Hasil dan Pembahasan}

Pada hasil dan pembahasan akan menguraikan mengenai hasil dari implementasi web $e$ commerce sambal nyoss dan hasil serta pembahasan dari pengukuran usability atau tingkat kepuasan pengguna menggunakan metode skala likert.

\subsection{Implementasi Sistem}

Implementasi sistem berisi mengenai implementasi sistem web e-commerce seperti halaman utama untuk pengguna dan halaman admin. Halaman depan berfungsi sebagai halaman utama, saat website sambalnyoss.com diakses. Pada halaman ini akan dibagi menjadi beberapa bagian, yaitu navigasi bar, menu kategori, menu banner, menu kontent, dan footer.

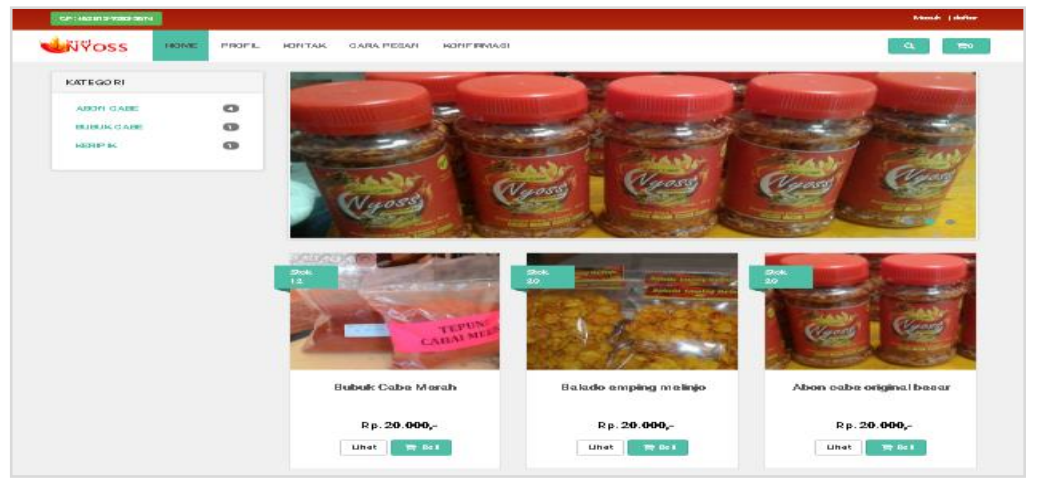

\section{Gambar 3. Halaman Utama}

Halaman utama tersebut memiliki Menu navigasi bar. Menu ini berisi top bar, yang berfungsi untuk fungsi login pelanggan dan navigasi bar, yang berisi menu-menu berfungsi untuk pergi ke suatu halaman. Terdapat juga icon pencarian dan icon keranjang. Sehingga apabila pengguna melakukan pembelian dapat dilihat melalui keranjang belanja. Terdapat menu kategori menu ini berfungsi untuk menampilkan daftar kategori produk yang dimiliki. Daftar kategori yang ditampilkan berupa daftar dan jumlah produk. Selain itu terdapat menu konten berfumgsi untuk menampilkan produk, halaman profil berfungsi untuk mengetahui profil UMKM dan footer yang berfungsi sebagai informasi tambahan website berupa alamat, facebook fans page serta media sosial lainnya seperti instagram, dan google+.

Sedangkan untuk halaman admin merupakan halaman pengelola atau administrator pada sistem e-commerce Sambal Nyoss. Halaman administrator dapat diperlihatkan pada Gambar 4.

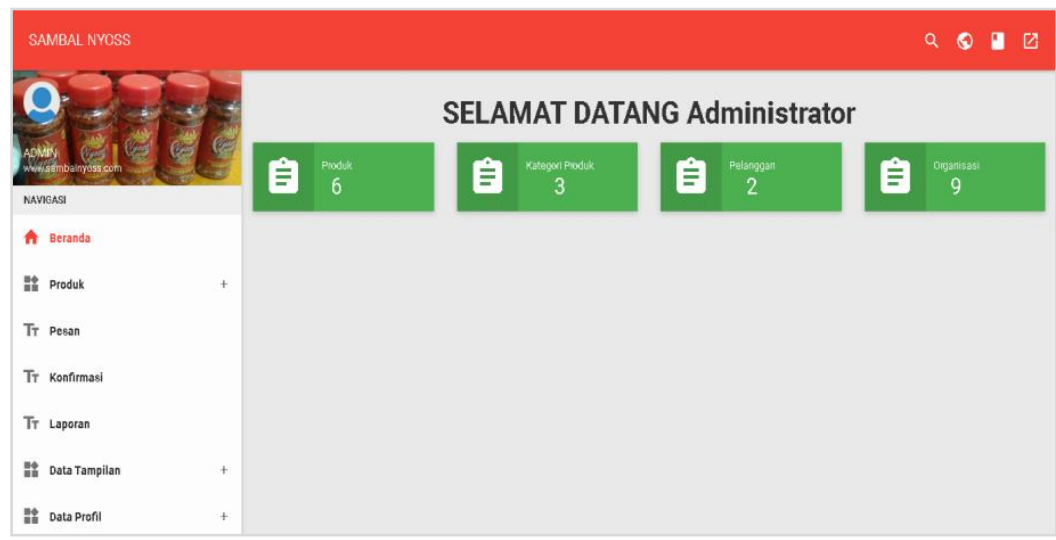

Gambar 4. Halaman Administrator

Halaman di bagian kiri adalah menu pengelola. Di menu tersebut terbagi dari beberapa halaman lagi yang mendefinisikan sesuai dengan fungsinya masing-masing. Dalam sistem $e$ - 
commerce sambal nyoss ini memiliki 10 menu, yaitu menu beranda, menu produk, menu pesan, menu konfirmasi, menu laporan, menu data tampilan, menu profil, menu data pelanggan, menu data admin, dan menu transaksi.

\subsection{Uji Coba Usability}

Untuk pengujian usabalitity dengan menggunakan metode skala likert adalah dengan menyiapkan pertanyaan-pertanyaan yang akan dijadikan acuan untuk menilai sistem oleh pengguna. Pengujian ini dilakukan oleh 30 responden secara acak. Sebelum responden memberikan nilai terhadap sistem, responden terlebih dahulu mencoba web e-commerce sambal nyoss tersebut. Agar penilaian terhadap sistem dapat fair maka responden harus melakukan percobaan sistem dengan tahapan seperti diperlihatkan pada Tabel 2.

Tabel 2 Tahap Pengujian Responden

\begin{tabular}{|c|l|}
\hline Tahapan & \multicolumn{1}{|c|}{ Kegiatan } \\
\hline 1 & $\begin{array}{l}\text { Membuka website } e \text {-commerce sambal nyoss } \\
\text { (sambalnyoss.com) }\end{array}$ \\
\hline 2 & $\begin{array}{l}\text { Mencoba mengklik menu navigasi seperti menubar dan } \\
\text { navigasibar }\end{array}$ \\
\hline 3 & $\begin{array}{l}\text { Mendaftar sebagi konsumen untuk mendapatkan username } \\
\text { dan password }\end{array}$ \\
\hline 4 & Login sebagai konsumen dan melakukan pembelian \\
\hline 5 & $\begin{array}{l}\text { Mencoba Login sebagai admin untuk menambah, } \\
\text { mengubah dan menghapus produk dan yang lainnya }\end{array}$ \\
\hline
\end{tabular}

Tahapan tersebut dapat diuraikan sebagai berikut :

Tahap 1 : Membuka website e-commerce sambal nyoss dengan memasukan alamat sambalnyoos.com, kemudian responden mencoba untuk melihat tampilan halaman utama website dan membaca informasinya tersedia.

Tahap 2 : Mencoba untuk mengklik menubar dan navigasibar. Menubar terletak di atas atau bawah header sedangkan untuk navigasibar terletak disamping kiri halaman utama.

Tahap 3 : Mencoba daftar ke web e-commerce sambal nyoss agar mendapatkan username dan password, kemudian melakukan login dan mencoba melakukan username atau password yang salah.

Tahap 4 : Melakukan login sebagai konsumen dan melakukan pembelian, setelah itu menambahkan atau menghapus pada keranjang belanja yang tersedia.

Tahap 5 : Melakukan login sebagai administrator, mencoba menambahkan produk baru, stok terbaru, menghapus beberapa produk dan mengedit serta melihat transaksi yang tersedia berserta laporan transaksi.

Kemudian responden diberikan pertanyaan dari kuesioner yang tujuannya untuk mengukur usability e-commerce sambal nyoss. Pertanyaan tersebut berisi 13 pertanyaan yang memiliki komponen usability. Nilai yang diberikan oleh responden yakni dengan skala 1 sampai 5 sesuai dengan Tabel 1.1 skala likert.

Komponen usability yakni

a. Learnability, menilai tentang tingkat kemudahan pengguna saat melakukan tahapan atau pengujian pada sistem e-commerce sambal nyoss.

b. Efficiency, menilai tentang seberapa cepat pengguna melakukan tahapan atau pengujian terhadap sistem e-commerce sambal nyoss.

c. Memorability, menilai tentang tinggkat kemudahan pengguna dalam menggunakan sistem 
dengan baik.

d. Errors, menilai terjadinya error pada sistem atau kesalahan yang dilakukan pengguna.

e. Satifaction, menjelaskan tingkat kepuasan pengguna dalam menggunakan sistem.

Hasil pengujian diperlihatkan pada Tabel 3.

Tabel 3. Hasil Ujicoba Usability dengan Metode Likert

\begin{tabular}{|c|c|c|}
\hline No & Pertanyaan & Rata Nilai Likert \\
\hline \multicolumn{3}{|c|}{ Aspek Sistem } \\
\hline 1 & Apakah tampilan menarik? & 4,05 \\
\hline 2 & Apakah mudah untuk dioperasikan? & 3,87 \\
\hline 3 & $\begin{array}{l}\text { Apakah pemilihan warna sudah sesuai dan tidak } \\
\text { membosankan? }\end{array}$ & 4,00 \\
\hline \multicolumn{3}{|c|}{ Aspek Pengguna } \\
\hline 4 & Apakah tampilan menu mudah dioperasikan? & 3,90 \\
\hline 5 & Apakah informasi mudah dimengerti? & 4,20 \\
\hline 6 & Apakah proses belanja mudah dioperasikan? & 4,10 \\
\hline 7 & $\begin{array}{l}\text { Apakah menu-menu yang tersedia mudah } \\
\text { dipahami? }\end{array}$ & 3,70 \\
\hline 8 & $\begin{array}{l}\text { Apakah simbol-simbol gambar mudah } \\
\text { dipahami? }\end{array}$ & 4,00 \\
\hline \multicolumn{3}{|c|}{ Aspek Interaksi } \\
\hline 9 & $\begin{array}{l}\text { Apakah mudah akses produk dan kategori yang } \\
\text { ditawarkan? }\end{array}$ & 4,00 \\
\hline 10 & $\begin{array}{l}\text { Apakah rincian produk sudah sesuai yang } \\
\text { ditawarkan? }\end{array}$ & 4,20 \\
\hline 11 & $\begin{array}{l}\text { Apakah aplikasi transaksi pembayaran mudah } \\
\text { dilakukan? }\end{array}$ & 2,96 \\
\hline 12 & $\begin{array}{l}\text { Apakah akses informasi setiap halaman mudah } \\
\text { dimengerti? }\end{array}$ & 4,10 \\
\hline 13 & Apakah menu dan tampilan mudah diingat? & 4,00 \\
\hline
\end{tabular}

Tabel 3 memperlihatkan bahwa hampir semua nilai adalah 4. Nilai 4 dalam skala likert merupakan kategori setuju, sehingga tingkat usability dapat diterima oleh pengguna. Walaupun terdapat nilai 2 dan 3. Nilai 3 terhadap menu yang terdapat pada website cukup dapat dimengerti bagi pengguna. Sedangkan untuk nilai skala 2 terdapat pada transaksi pembayaran, sebab transaksi pembayaran masih menggunakan sistem transfer bank, belum dapat secara otomatis melalui sistem e-commerce seperti paypal dan doku.

\section{Kesimpulan}

Hasil ujicoba web e-commerce terhadap pengujian usability menggunakan metode skala likert dapat disimpulkan bahwa rata-rata nilai skala likert dari pengujian usability yakni 4 . Nilai 4 dalam skala likert merupakan kategori setuju, sehingga tingkat usability dapat diterima oleh pengguna. Hasil pengujian tersebut juga mengartikan bahwa web e-commerce sambal nyoss telah memenuhi nilai aspek usability seperti kemudahan sistem, sistem mudah diingat, efisiensi, tidak terjadi kesalahan atau error dan memiliki tingkat kepuasan pengguna. 


\section{Daftar Pustaka}

[1] U. Hasanah, "Sistem Informasi Penjualan On_Line Pada Toko Kreatif Suncom Pacitan," IJNS-Indones. J. Netw. Secur., vol. 4, no. 3, 2013.

[2] T. I. Tjendrowaseno, "Pembuatan Website Profil Sekolah Menengah Pertama Negeri 2 Karangmalang Sragen,” IJNS-Indones. J. Netw. Secur., vol. 3, no. 1, 2013.

[3] D. A. Rivai, "Pembuatan Website Profil Sekolah Menengah Kejuruan (SMK) Miftahul Huda Ngadirojo," IJNS-Indones. J. Netw. Secur., vol. 2, no. 3, 2012.

[4] A. T. Wibowo, "Pembuatan Aplikasi E-Commerce Pusat Oleh-Oleh Khas Pacitan Pada Toko Sari Rasa Pacitan,” IJNS-Indones. J. Netw. Secur., vol. 2, no. 4, 2012.

[5] D. R. Rahadi, "Pengukuran usability sistem menggunakan use questionnaire pada aplikasi android," J. Sist. Inf., vol. 6, no. 1, 2014.

[6] S. Syofian, T. Setiyaningsih, and N. Syamsiah, "Otomatisasi metode penelitian skala likert berbasis web," Pros. Semnastek, 2015. 